\section{Pediatria \\ HORMÔNIO ANTI-MÜLLERIANO: IMPORTÂNCIA NA PRÁTICA PEDIÁTRICA}

O Hormônio Anti-Mülleriano (AMH), também chamado de Substância Inibidora Mülleriana (MIS), é uma glicoproteína dimérica de 140 kilodaltons que sofre ativação após a clivagem e liberação dos fragmentos Cterminais (partículas biologicamente ativas). $\mathrm{O}$ AMH pertence à família do TGFb ("Transforming Growth Factor b"), e está envolvido em processos de crescimento e diferenciação.

O gene que codifica o AMH está localizado na extremidade do cromossomo 19, regiões 13.2 a $\mid 3.3$, possui cinco exons e tem sua transcrição controlada pelo fator esteroidogênico I (SF-I), SOX9 (SRYHMG Box related gene 9), WTI (Tumor de Wilms I), e GATA4 ("zinc finger"), enquanto que o controle após a etapa de tradução é feito pela testosterona.

$\mathrm{O}$ AMH age por meio de duas classes de receptores que são na realidade serina-treonina kinases: os do tipo Il foram clonados em 1994 e são expressos apenas nos órgãos-alvo do AMH; os do tipo I (BMPR-IB e seu efetor Smad I, fator nuclear kappa B, beta-catenina e fator pl 6 ativado), possuem mecanismos de ação ainda desconhecidos.

Durante o desenvolvimento do feto, as gônadas apresentam um duplo potencial de transformação, pois os dutos de Müller e os canais de Wolf coexistem: os primeiros são precursores do útero, das trompas de Falópio e dos dois terços superiores da vagina; os canais de Wolf formam o epidídimo, os canais deferentes e as vesículas seminais. No menino, o AMH, fator testicular secretado pelas células de Sertoli, causa a regressão dos dutos de Müller e continuará a ser produzido até a puberdade. Após este período, os níveis decrescem lentamente até atingirem valores residuais. Na menina, o AMH começa a ser produzido em pequenas quantidades pelas células da granulosa ovariana logo após o nascimento até a menopausa, tornando-se indetectável no soror após este período. $O$ $\mathrm{AMH}$ age por meio de uma diminuição da atividade da enzima aromatase nas células da granulosa ovariana.

A descida dos testículos para a região inguinal constitui um evento complexo mediado pela descendina, hormônio que induz o crescimento seletivo das células do gubernáculo, e ainda por fatores mecânicos (pressão intra-abdominal). A descida dos testículos depende de uma inter-relação entre a pressão intra-abdominal transmitida pelo "processus vaginalis" patente, e a regressão do gubernáculo induzida por hormônios androgênicos. Anormalidades funcionais em qualquer um dos fatores resulta em criptorquidia.

Durante a puberdade, a expressão de AMH é regulada negativamente por hormônios androgênicos e diminui drasticamente nos túbulos seminais. Vários estudos demostraram que os níveis de AMH apresentam uma relação inversa em relação aos níveis de testosterona, porém correlacionam-se melhor com o desenvolvimento pubertário. Níveis séricos baixos de AMH são observados tanto nos pacientes com puberdade precoce de origem central (hipotalâmica) quanto naqueles nos quais o mecanismo fisiopatológico independente de gonadotrofinas, o que sugere que estas últimas não participem da retro-regulação do AMH na puberdade. Nestes pacientes, os níveis de AMH retornam aos valores encontrados na infância 3 a 6 meses após 0 tratamento. Em pacientes que apresentam defeitos na produção de hormônios androgênicos, os níveis séricos de AMH atingem valores anormalmente elevados no período neonatal e pré-puberal, o que sugere um possível papel estimulador das gonadotrofinas, observado apenas quando os efeitos supressores dos hormônios androgênicos estão ausentes.

$\mathrm{O}$ AMH também afeta a função do testículo no indivíduo adulto, pois promove o bloqueio da diferenciação das células do mesênquima em células de Leydig, além de diminuir a expressão de enzimas esteroidogênicas de maneira independente. $\mathrm{Na}$ mulher, o AMH apresenta flutuações durante o ciclo menstrual, sugerindo uma função reguladora da foliculogênese. Não obstante, não foi encontrada uma correlação significativa entre os níveis de $\mathrm{AMH}$ e de gonadotrofina coriônica. Em algumas situações, tais como na Síndrome dos Ovários Policísticos (PCOS), no diagnóstico de tumores da granulosa ovariana, e ainda nas recidivas de tumores após o tratamento específico tanto em mulheres quanto em homens (câncer de próstata), o AMH apresenta-se elevado.

A dosagem de $\mathrm{AMH}$ também permite a avaliação dos estados intersexuais (hermafroditismo), pois é capaz de distinguir os casos de defeitos da diferenciação sexual masculina causados pela presença de testículos anormais, daqueles que possuem defeitos de secreção e/ou ação da testosterona.

Na Síndrome da Persistência do Ducto Mülleriano (PMDS), entidade genética rara de herança autossômica recessiva que causa defeitos na síntese e ação do $\mathrm{AMH}$, os indivíduos portadores de cariótipo $46 \mathrm{XY}$ e fenótipo masculino normal apresentam criptorquidia bilateral, hérnias inguinais e genitália masculina, porém freqüentemente apresentam útero e trompas de Falópio no canal inguinal ou no abdomen.

Finalmente, mutações no gene do AMH ou em seus receptores epecíficos são responsáveis por níveis muito baixos ou indetectáveis de AMH. No entanto, os níveis de $\mathrm{AMH}$ serão normais em pacientes que apresentam uma falta de sensibilidade dos órgãos-alvo.

A dosagem de AMH constitui um instrumento útil para o diagnóstico de várias entidades clínicas, tais como a puberdade precoce (AMH baixo), a puberdade tardia (AMH alto); o pseudo-hermafroditismo masculino, a Síndrome da Persistência do Ducto Mülleriano (PMDS); a suspeita de anorquia ou ectopia testicular. Poderia ainda auxiliar na determinação do sexo fetal, sobretudo em presença de aberrações cromossômicas. OAMH também tem sido utilizado para confirmar a retirada completa de tecido gonadal tumoral após cirurgias.

Muito embora um kit comercial para a avaliação do AMH em soro ou plasma já se encontre disponível no mercado, trata-se de um produto novo que ainda carece de uma validação clínica mais extensa.

Thelma Suely Okay 


\section{Referências}

I. Josso N, Legeai L, Forest MG, Chaussain JL, Brauner R. An anzyme linked immunoassay for anti-Müllerian hormone: a new tool for the evalluation of testicular function in infants and children. J Clin Endocrinol Metab. 1990; 70(I): 23-27.

2. Lee MM, Donahue PK, Hasegawa T, Silver- man B, Crist GB, Best $S$, et al. Müllerian inhibiting substance in humans: normal levels from infancy to adulthood. J Clin Endocrinol Metab 1996; 8I(2): 57I-6.

3. Lee MM, Donahue PK, Silverman BL, Hasegawa Y, Gustafson ML, Chang YC, et al. Measurements os serum mullerian inhibiting substance in the evaluation of children with nonpalpable gonads. N England J Med 1997; 336 (2I):I480-6.

4. Rey RA, Belville C, Nihoul-Fékété C, Michel-Claemard L, Forest MG, et al. Evaluation of gonadal function in 107 intersex patients by means of serum antimüllerian hormone measurement. J Clin Endocrinol Metab. 1999; 84 (2): 627-31. 